\title{
The Risk of Water, Sanitation and Hygiene on Diarrhea-Related Infant Mortality in Eastern Ethiopia: A Population-based Nested Case-Control
}

Samuel Mebrahtom ( $\square$ samrontom@gmail.com )

Addis Ababa University, Ethiopian Institute of Water Resources

Alemayehu Worku

Addis Ababa University

Daniel Gage

University of Connecticut

\section{Research Article}

Keywords: Diarrhea-related Infant Mortality, Risk factors, Water, Sanitation and Hygiene

Posted Date: December 8th, 2020

DOI: https://doi.org/10.21203/rs.3.rs-116039/v1

License: (c) (1) This work is licensed under a Creative Commons Attribution 4.0 International License.

Read Full License

Version of Record: A version of this preprint was published at BMC Public Health on February 18th, 2022. See the published version at https://doi.org/10.1186/s12889-022-12735-7. 


\section{Abstract}

Background: Diarrhea is still appeared to be as one of the leading global killers and disability-adjusted life-years lost, particularly in the infant and children. As per WHO, about $88 \%$ of diarrhea-related deaths are attributable to unsafe water, inadequate sanitation and insufficient hygiene, mainly in developing world. Thus, the main objective of this study was to find out the risk of such factors that contribute for diarrhea-related infant mortality in Eastern Ethiopia.

Methods: This study employed community based unmatched nested case-control study design in Eastern Ethiopia. The cases were infants who died from diarrheal disease while controls were those who survived their first year of life from September, 2016 to August, 2018. A total of 305 study subjects (61 cases and 244 controls) were included in the study. Infants dying from diarrhea were compared to four neighborhood controls in terms of several risk components of Water, Sanitation and Hygiene. Data were collected from mothers/care takers of infants using pre-tested structured questionnaires, and entered onto CSpro version 5.1 and transform to SPSS version 23 to analyzed potential risk factors.

Findings: Finding of this study revealed that the risk factors such as age of mother with $<20$ years old, unsafe drinking water storage, infants in households without point-of-use water treatment practices, households with unimproved sanitation status, unsafe disposing of child faeces and improper management of solid waste found to be significantly less likely to contribute infants dying from diarrhea than those with their reference group. Infants in households with improper management of liquid waste management strongly association which had three times more likely to occur diarrhea-related infant death (AOR: 3.43, 95\% Cl: 1.34, 8.76). Infants whose mother/caretaker practiced hand washing with less critical time (one-two occasions) had three times greater risk to infant death from diarrhoea than those who had practice more than three critical times of hand washing (AOR: 3.04, 95\% Cl: 1.13, 8.17).

Conclusion: This study suggests that infants in households with improper management of liquid waste and hand washing practices with fewer occasions (one-two critical time) are a greater risk of getting a diarrhea-related infant death. Therefore, efforts should be made to ensure intervention taking such risk factors into consideration, typically in the infantile period. Key words: Diarrhea-related Infant Mortality, Risk factors, Water, Sanitation and Hygiene

\section{Background}

Diarrhoea is a major cause of morbidity and mortality, in particular, among infants and children worldwide(1). It is still appeared to be as one of the leading global killers(2) and disability-adjusted lifeyears lost $(3,4)$. According to the World Health Organization, more than half a million of diarrheal-related deaths reported among under five children each year in worldwide $(5,6)$. In 2017, diarrhea was responsible for about 7.8 percent of all worldwide deaths to children $<5$ years of age(7). Around $90 \%$ of all diarrheaassociated deaths occur in children under five years of age in low-and-middle income countries $(8,9)$. 
Although the total annual number of deaths from diarrhea decreased significantly among children $<5$ years over the period 1990 and 2017 in worldwide (10), diarrhea-related death remained highest in some of the world's developing countries, particularly in south Asia and sub-Saharan Africa where $78 \%$ of childhood diarrheal deaths occurred(11). The top five countries where the most diarrhea deaths among children occurred in 2016 include: Nigeria, India, Pakistan, Democratic Republic of Congo and Ethiopia $(11,12)$. Although the majority of diarrhea cases occur in developing countries, industrialized nations also experience a considerable burden from diarrhea(13).

Infants ( $<1$ year of age) is being placed at the highest death from diarrhea among children under 5 years of age $(13,14)$. Hence, paying a particular attention to this age group will turn down a marked effect on infant mortality. Diarrhea has been shown to be one of the main causes of infant mortality and its burden is still a serious concern in Ethiopia. Although the trend of under five deaths due to diarrhea decreased from $16 \%$ to $8 \%$ between 2000 and 2016 , the reduction of diarrhea death in infants ( $<1$ year of age) observed to be unsteady.

Diarrhea is commonly defined as the passage of loose or watery stools occurring three or more times in a 24-hour period, and causes death by depleting body fluids resulting in profound dehydration. Diarrhea can have a harmful impact on childhood growth and cognitive development(15). It can be easily treatable and preventable(16-18). There are multiple risk factors that likely to be responsible for the cause of childhood diarrhea-related mortality. Among these factors, about $88 \%$ of diarrhea-associated deaths are attributable to unsafe water, inadequate sanitation, and insufficient hygiene $(19,20)$. Almost all $(99.8 \%)$ of deaths associated with these risk factors are in developing countries(9).

Publications on diarrheal death related risk factors were rare(21), particularly in sub-Sahara Africa. Indeed, many studies were conducted on under five predominantly in diarrheal morbidity(22), and studies on risk factors that makes diarrhea-related death more likely to happen particularly on infants ( $<1$ year of age group) were very much limited. Hence, there is need such extensive study which helps to develop better understanding for selecting strategies in reducing the death due to diarrhea. Accordingly, the main objective of this particular study was to identify the risk of drinking water supply, sanitation and hygiene components that contribute to diarrhea-related infant mortality in Eastern Ethiopia. This study assumed to be filled the existing gap and enable policy and decision makers to develop preventive strategy that can help infant survival against diarrhea.

\section{Materials And Methods}

Study Setting: This study was conducted in six randomly selected districts in West Hararghe administrative zone of Oromia region and Zone 3 of Afar region, which are situated in Eastern part of Ethiopia. The districts includes Chiro, Mieso, Gemechis and Tullo districts of West Hararghe administrative zone of Oromia while Amibara and Awash Fentale districts that comprised in zone 3 administration of Afar region. Based on the 2007 National Population and Housing Census of Ethiopia(23), the projected population estimate for the year 2016 to each districts; Chiro $(223,167)$, Mieso 
$(176,200)$, Gemechis $(241,949)$, Tullo $(194,791)$, Amibara $(80,531)$ and Awash Fentale $(37,892)$. Of the total population, $3.4 \%$ are under the age of one year in the national context. The study area has two main climate seasons - a dry season and a rainy season: The dry season ranges from October to February while the rainy seasons have two periods - the period from June to September is the main rainy season and some rainy weather period usually from March to May.

Study Design: The study employed community based nested unmatched case-control study, which was nested from longitudinal survey conducted to identify cause of infant mortality from September, 2016 to August, 2018 in Eastern Ethiopia.

Study Population: The study population (mother-infant pair) consisted of cases and controls drawn from the longitudinal survey conducted in the randomly selected study area. Cases were infants who died from diarrheal disease while controls were those who survived their first year of life.

\section{Sample Size Determination}

The sample size was computed using Openepi version 3.03a, and calculated with the sample size for unmatched case control study. The sample size was calculated for each variable taking the result of the study conducted previously that would allow to taking the largest sample size. Accordingly, the sample size was determined based on the assumption that the proportion of latrine of the household as a risk factor for diarrhea-related infant death among the household of controls to be $15.4 \%$ and $5.93 \%$ for cases(21), two-sided significance level (1-alpha) $=95 \%$, Power (1-beta, $\%$ chance of detecting) $=90$, Ratio of Unexposed to Exposed in sample $=1: 4$, to detect an odds ratio of 0.29 . Thus, the minimum sample size required for the study estimated to be 290 (58 cases and 232 controls). Because of many reasons of uncertainty and possible non-response, $10 \%$ were added, thus the final sample size resulted as 319 (64 cases and 255 controls).

\section{Sampling Technique}

The sampling techniques for this particular study exploit all diarrheal deaths of infants, which were selected as cases while density sampling used for the control groups. The entire cases (infant died from diarrhea) that ascertained by electronics verbal autopsy were directly taken from the longitudinal survey. Infants who had survive their first year were eligible for selection as control group, which were randomly selected from the adjacent area linked to that of the infants died due to diarrhea. For each case, four neighborhood controls were randomly selected from the longitudinal survey database and compared in terms of socio-demographic and several risk components of Water, Sanitation and Hygiene.

Data Collection Instrument and Methods: Data were collected by trained data collectors using structured and pre-tested questionnaire and conducted under closely overseen by supervisors. The questionnaire was prepared based on WHO, UNICEF and national standards as well as adopted from relevant literatures $(24,25)$. This questionnaire was first developed in English, then translated into both "Amharic" 
and "Afan Oromoo", and back translated into English to ensure its meaning of questions is retained and checked consistency. The respondents were mothers or primary caretaker of the infants ( $<1$ year of age).

\section{Data Quality Control:}

Data quality was assured by controlling both random and systemic error. Data quality was maintained through properly designed data collection tool, and data collectors as well as supervisors recruited with the relevant educational background and language proficiency. Training was held and pre-test carried out in a community with similar characteristics. The data collection procedures developed and the collected data were reviewed by principal investigator. Any identified errors were discussed and immediate measure has been taken.

\section{Data Management and Analysis:}

The collected data were entered into CSPro version 6.1 then transformed to SPSS version 23 for analysis. Descriptive statistics such as frequency distribution and cross tabulation were made to summarize the study variables. Both bivariate and multivariable conditional logistic regression was used to estimate crude and adjusted odds ratios with $95 \%$ confidence intervals for the association between risk factors and diarrhea-related infant death. Bivariate conditional logistic regression for each variable was analyzed and any risk factors that showed marked association ( $p$-value $\leq 0.25$ ) were considered as candidate for multivariable logistic regression. The Hosmer-Lemeshow goodness-of-fit test was checked and indicated as this model is valid seeing that the $p$-value is greater than 0.05 . Variables that resulted $P$ value $\leq 0.05$ in the multivariable logistic regression were affirmed as significantly associated with the outcome variable (diarrhea-related infant death).

\section{Operational Definitions}

Water Accessible: People access to $25 \mathrm{l} / \mathrm{c} / \mathrm{d}$ within $1 \mathrm{~km}$ radius from improved water supply sources for rural community(25)

Households adequate water treatment at point-of-use: Boiling, Add bleach/chlorine, Water filter (ceramic, sand, composite) and Solar disinfection(24)

Safe Water Storage: Water stored in plastic, clay or metal pot narrow mouth (usually diameter of $3 \mathrm{~cm}$ or less), have a lid or secured cover and a tap (spigot), cleaned and kept cover(26)

Improved Sanitation: flush/pour toilet, Ventilated Improved Pit (VIP) latrine, Simple pit latrine with slab (slab that can be cleaned), Composting toilet(24)

Access to hand washing facilities near to latrine: Presence of hand washing station within 3 meters of the latrine with water and soap/substitute.

Critical time of Hand washing: Hand washing with soap or substitute at critical times (the most recommended occasions): after using latrine, after cleaning child bottom, before preparing food, before 
feeding child, before breastfeeding.

Safe disposal of children's faeces: Child used toilet/latrine, put/rinsed faeces into the toilet/ latrine and buried the faeces(24)

Proper Solid Waste Management: households dispose their wastes to waste collection tank, provide to private waste collection groups, buried and/or burn, and composting.

Proper liquid Waste Management: Households dispose their liquid wastes through infiltrate to the ground, cesspool (a pit dug in the ground to receive liquid waste) and dumping to municipal disposal sites.

\section{Results}

\subsection{General Characteristics of Study Subjects and Respondents}

A total of 305 study subjects ( 61 cases and 244 controls) were included in the study, which yields the non-response rate $4.7 \%$ and $4.3 \%$ for case and control, respectively. Among these studied subjects, 61 were infants who died as the result of diarrheal disease (cases) ,and 244 were those who survived their first year of life (controls), which was nested in a longitudinal survey database (from September 2016 to August 2018) residing in Eastern Ethiopia.

\subsection{Socio-demographic characteristics associated with infant diarrheal death}

Of the Interviewed infants' mothers/caretakers, the mean age ( \pm SD) of the respondent among cases (infant who died due to diarrhea) was $26.8( \pm 3.9)$ years old and $27.8( \pm 4.5)$ for controls (infant who survived their first year of life). Majority of the infants mothers of the cases fall within the youth age group of $20-34(90.2 \%)$, while it was (82.0\%) for the controls. About $44.3 \%$ of cases and $48.4 \%$ of controls had history of having borne two to four viable offspring (Parity). The mean ( \pm SD) family size of households with infants in the cases was $4.70( \pm 1.98)$ and $4.99( \pm 1.96)$ for controls. Majority of the study participants were married at ( $96.7 \%$ of cases and $98.0 \%$ of controls). Oromo ethnic group comprises the largest proportion of the study subjects ( $90.2 \%$ of cases and $87.3 \%$ of controls). Muslim followers were larger in the study participants at $98.4 \%$ for cases and $88.5 \%$ for the control group. The majority of the respondents ( $88.5 \%$ of cases and $74.2 \%$ of controls) were not educated. Likewise, most of the spouse of the cases $(78.7 \%)$ was uneducated as compared with the controls $(65.2 \%)$. Almost equal proportion of the cases $(90.2 \%)$ and the controls $(90.6 \%)$ were housewives by occupation. Spouse's occupational status between the two-study groups indicated that about $(90.2 \%)$ cases and $(85.7 \%)$ controls were found to be farmers/own farm labor. High proportion of controls (50.8\%) compared with that of cases (45.9\%) had an average household monthly income of more than and equal to 570 ETB.

The bivariate analysis between socio-demographic characteristics and diarrhea-associated infant death indicated that mothers and spouse's level of education were bivariately associated with infant's diarrheal death. In this analysis, it was estimated that the infants whose mothers were not educated had less likely for risk of infant death as a result of diarrhea than those whose mothers had reached at some level of 
schooling ( $P=0.021, \mathrm{COR}: 0.37,95 \% \mathrm{Cl}: 0.16,0.86)$. Likewise, the death of infants due to diarrhea was less likely to occur for the uneducated spouse than educated ( $P=0.046, \mathrm{COR}: 0.51,95 \% \mathrm{Cl}: 0.26,0.98)$ (see Table 1).

\subsection{Environmental Variables (Water Supply, Sanitation and Hygiene) Associated with Risk of Infant death due to Diarrhea}

The distribution of cases and controls as well as bivariate analysis in the different categories of Water supply, Sanitation and Hygiene presented as follows:

\subsubsection{Risk of access and use of water supply associated with infant's diarrheal death}

Almost equal proportion of case (78.7\%) and control (78.3\%) group of infant's households were used improved water sources. The household's time to access water source resulted with 30 minutes or less ( $65.6 \%$ of case and $62.7 \%$ of control). About $85.2 \%$ of cases and $82.0 \%$ controls accessed water within $1 \mathrm{~km}$ radius from their dwelling. Most of the infants in the households with the daily water consumption per capita per day among case and control group appears to be $88.5 \%$ and $75.4 \%$, respectively. The vast majority of cases $(91.8 \%)$ and controls (79.1\%) among infants in the households found with water inaccessibility (Water Consumption Per Capita per day with less than $25 \mathrm{l} / \mathrm{c} /$ day in more than $1 \mathrm{~km}$ radius). High proportion of cases $65.6 \%$ compared with that of control (40.2\%) found to have unsafe drinking water storage. Majority of controls $(65.2 \%)$ compared with case $(52.5 \%)$ reported to know at least one and more households point-of-use drinking water treatment methods. However, about $80.3 \%$ of the cases and $61.5 \%$ of controls' group have ever practiced water treatment at household's point-of-use.

The risk of water access and use components bivariately associated with diarrheal-related infant death included Water quantity - Water Consumption Per Capita per day with less than $25 \mathrm{l} / \mathrm{c} /$ day, households water inaccessibility, households with unsafe drinking water storage, households reported as did not practices water treatment at Point-of-use. The bivariate analysis of this study indicated that Water quantity - Water Consumption Per Capita per day with less than $25 \mathrm{l} / \mathrm{c} /$ day $(P=0.031, \mathrm{COR}: 0.40,95 \% \mathrm{Cl}$ : $0.17,0.92)$, Households Water Inaccessibility $(P=0.028$, COR: $0.34,95 \% \mathrm{Cl}: 0.13,0.89)$, Households with unsafe drinking water storage ( $P<0.001, \mathrm{COR}: 0.35,95 \% \mathrm{Cl}: 0.20,0.63)$, Households reported as did not practices water treatment at Point-of-use ( $P=0.007, \mathrm{COR}: 0.39,95 \% \mathrm{Cl}: 0.20,0.77)$ were less likely to occur infant death due to diarrhea (see Table 2).

\subsubsection{Risk of sanitation associated with infant's diarrheal death}

About $65.6 \%$ of the cases and $76.2 \%$ of controls infants in the households had their own latrine. Nearly a similar proportion of households in cases and controls have practiced open defecation (21.3\% for cases and $20.1 \%$ for controls). The household's latrine utilization appears to be $60.7 \%$ in cases and $71.3 \%$ in the control group. Less than half of the study subject (39.3\%) in cases and about $49.6 \%$ in controls have found with cleaned latrines. Hand washing facilities near to latrine comprises the lowest proportion in case (18\%) than in the control (50\%). The majority of cases (83.6\%) compared with controls $(66.4 \%)$ in 
the households found with unimproved sanitation status. Unsafe disposes of child feaces in the households appears in large in cases (70.5\%) than in control (39.8\%). About $54.1 \%$ of cases and $79.9 \%$ of controls in the households dispose solid wastes in improper way. Majority of cases (82.0\%) as compared with controls $(57.4 \%)$ found with unsafe disposal of liquid wastes by the households.

In the bivariate analysis, households with unimproved sanitation ( $P=0.011, \mathrm{COR}: 0.39,95 \% \mathrm{Cl}: 0.19,0.80)$, Households with unsafe disposing of child feaces ( $P<0.001$, COR: $0.28,95 \% \mathrm{Cl}: 0.15,0.51)$, Households with improper management of solid waste $(P<0.001$, COR: $0.21,95 \% \mathrm{Cl}: 0.12,0.39)$ were less likely to occur infant death as a result of diarrhea. However, infants in the households who disposed liquid waste unsafely were 3.4 times more likely at risk of diarrheal-associated infant death as compared to infants in the households who properly managed it ( $P=0.001$, COR: $3.38,95 \% \mathrm{Cl}: 1.68,6.80)$ (see Table 3 ).

\subsubsection{Risk of hygiene associated with infant's diarrheal death}

The result showed that about $29.5 \%$ in case group and $9.8 \%$ in controls of the respondents reported as did not washing their hands at any critical time. Handwashing practices was scored less than three critical time of Hand washing, which shows almost similar proportion in both comparative groups $159.0 \%$ for cases and $59.5 \%$ for controls). The vast majority of cases (83.6\%) compared with controls (32.0\%) of households reported not used any agents during handwashing.

In the bivariate analysis, infants in the households did not practice hand washing in any critical time at all were less likely to occur infant diarrheal death as compared to households practiced three and more critical time of Hand Washing ( $P=0.025$, COR: $0.38,95 \% \mathrm{Cl}: 0.16,0.89)$. In contrary, infants in the households practiced less than three critical time of Hand washing was three times more likely to have diarrhea related death than households practiced three and more critical time of Hand Washing $(P=0.002$, COR: $3.02,95 \% \mathrm{Cl}: 1.48,6.16)$. The occurrence of diarrhea death among infant's households who did not use agents (water with soap or ash/abrasives) during hand washing was two times higher than those who used agents ( $P=0.030$, COR: $1.91,95 \% \mathrm{Cl}: 1.07,3.43)$ (see Table 4$)$.

\subsection{Multivariable's Conditional Logistic Regression Analysis}

In the multivariable conditional logistic regression, the risk factors that were significantly associated with infant diarrheal death identified includes age of mother with $<20$ years old, unsafe drinking water storage, infants in households without point-of-use water treatment practices, households with unimproved sanitation status, households with unsafe disposing of child feaces, households with improper management of solid and liquid waste, households with lesser hand washing practices at critical time.

In this analysis, infants whose age of mother being lower than 20 years old had significant relationship with less likely to occur infants death due to diarrhea as compared to those reference group of age $\geq 35$ years (AOR: 0.01, 95\% Cl: 0.01, 0.47). However, Mother's religious status, Mothers and spouse's level of education did not show statistically significant association with infant's diarrheal death, particularly after adjustment. 
Infants in households with unsafe drinking water storage were less likely to increased risk of infants death from diarrhea with an estimated odds ratio of 0.38 in the comparison than in the households with safe drinking water storage (AOR: $0.4,95 \% \mathrm{Cl}: 0.18,0.81$ ). Those households who didn't treat drinking water at point-of-use were less likely to be at risk of having infant death from diarrheal than those treated their drinking water (AOR: $0.21,95 \% \mathrm{Cl}: 0.08,0.61$ ).

The occurrence of diarrheal death among infants in households with unimproved sanitation status was less likely than households with those improved sanitation (AOR: $0.36,95 \% \mathrm{Cl}: 0.13,1.00$ ). Compared to households with the safe disposing of child faeces, those disposing unsafely were found with an increased odds of infant death due to diarrhea (AOR: $0.34,95 \% \mathrm{Cl}: 0.15,0.81$ ). Infants who died from diarrhea were less likely to happen in the households disposing solid wastes improper than those properly managed (AOR: $0.29,95 \% \mathrm{Cl}: 0.13,0.66)$.

Households with improper management of liquid waste management found with strong association with more than three times more likely to occur diarrhea-associated infant death as compared to those with proper liquid waste management (AOR: $3.43,95 \% \mathrm{Cl}: 1.34,8.76$ ). Infants whose mother/caretaker practiced hand washing with less critical time was three times greater risk to infant death from diarrhoea than those who had practice more than three critical times of hand washing (AOR: 3.04, 95\% Cl: 1.13, 8.17) (see Table 5).

\section{Discussion}

Despite reduction of diarrheal-related death is observed in the last three decades worldwide, the number of deaths remains high(27). Most deaths as the result of diarrhea existed in sub-Saharan Africa and Southeast Asia combined contain $78 \%$ of death from all diarrhea deaths occurring among children in the developing world (16). Most of those diarrhea-related deaths are appeared in small children(28,29). A child under the age of one is likely to have more diarrhea-associated death(13). Infants are susceptible to the incidence and a subsequent risk of deaths as a result of diarrhoea due to a combination of factors. Along with biological and social factors, environmental factors are one of the main risk factors that contribute for the death of infants from diarrhea. Understanding of such risk factors is indispensable in developing public health prevention strategy, aimed to decrease risk of diarrhea-related infant mortality.

The present study has attempted to look into possible contributing risk factors for diarrheal-related infant death, in particular, on Water supply, Sanitation and Hygiene. Unsafe water, poor sanitation and hygiene are the leading risk factors for diarrhea death in worldwide(17,19,30). In our study, infants whose age of mother being lower than 20 years old had significant relationship with occurrence of infant's diarrheal death as compared to the reference group (age $\geq 35$ years). This finding is consistence with a casecontrol study conducted elsewhere, which reported that those infant's mother with lower age were significantly associated with the risk of diarrhea-associated infant death, particularly among those with normal birth weight(31). 
With respect to access and use of water supply components, our analysis showed that infants in households with unsafe drinking water storage and households without point-of-use water treatment practices have significant association to the risk of death due to diarrhea, after adjusting for the effect of other variables. The estimated odds ratio that increased unsafe water storage is significantly associated with the risk of infants dying as the result of diarrhea is 0.4 in adjusted analysis. In other words, better access to household's safe water storage is associated with decreased diarrhea-associated infant mortality. The national study highlighted that storage water quality issues are a great public health concern in rural Ethiopia(32). The risk associated with untreated water practices at household's level is significant with the corresponding odds ratio of 0.2 for getting infant's diarrheal death than without such practices. This finding is contrary with earlier study conducted in southern Brazil(21), as it was revealed that those using untreated water had no statistical significant with the risk of death from diarrhea. Basically, the use of unsafe water either for drinking purpose or food preparation puts infant's health at risk, which leads to a subsequent risk of deaths. It can be seen from the report that millions deaths occur each year from water-related diarrhea alone(33), as well as caused by unsafe water(34).

As of 2016, only 7\% of households in Ethiopia is using appropriate households water treatment methods(35). WHO recommended that households water treatment and safe water storage is an important public health intervention to improve the quality of drinking-water and reduce diarrheal disease(36). In view of this, study conducted in Zambia tested as aforementioned intervention is a fundamental tool for preventing water-borne disease(37).

On the sanitation aspects, our analysis indicated significant relationship is observed for households with unimproved sanitation status and risk of infant death due to diarrhea. Our finding underpin the conclusion made by different studies(38), and also an ecological study conducted for 193 countries indicated that increasing access to improved sanitation was significantly associated with decreased infant mortality rate(39). Similarly, those responsible for the largest declines (13.3\%) in the diarrhoea mortality rate were reduction in exposure to unsafe sanitation in children(40). As of 2016, access to improved sanitation in Ethiopia remains alarmingly low with an estimated coverage of $6.3 \%(35)$, and more effort is needed. Our analyses have been also found that unsafe disposing of child feaces significantly associated with infant death due to diarrhea. Many cultures consider the stools of infants are harmless(41), which can poses a greater health risk. The findings further indicated that improper management of solid wastes significantly associated with infant death due to diarrhea. Improper disposing of domestic solid waste could be one of the suitable sites for spread of pathogens that can leads to children's morbidity and followed by mortality.

Prominently, the analysis of our study showed that improper management of households liquid wastes had a positive influence with greater magnitude in infant's death from diarrhea. The risk of death from diarrhea was more than three times higher in infants living in the households with improper liquid waste disposal than in those disposed in proper way. Reliance on scientific explanation, this might be attributed to the potential source of breading sites for flies which can carry enteric pathogens and mediate route to contaminate children's water and food. An unsafe environment places children at risk of death(42). These 
domestic liquid wastes come from their day-to-day living and includes those from food preparation, washing, bathing and toilet usage.

Despite the fact of human hands is one of the main vehicles for transmitting diarrhea disease, the role of poor handwashing practices at critical time as a risk factor had strong relationship with infant death from diarrhea. Our study demonstrated that those self-reported household's practiced handwashing in less occasions (One to two critical times') increases risk of infant deaths from diarrhea by 3-fold greater compared with those washed their hands at three and more critical times. Regardless of its magnitude, different studies indicated the significant link between handwashing practices and diarrhea morbidity and mortality(43-45). The handwashing practices at critical time mainly in mothers of children is poor according to inland study(46). Evidences indicated that handwashing at critical times reduce diarrhea rated by almost 40 percent(47), which could be resulted significant reduction in mortality.

\section{Strength and limitation:}

The strengths of this study include as it used nested case-control study design which is valid and efficient design and can minimized both selection and recall bias. Despite such studies is available insufficiently at population level, in particular, this study could provided useful information for building evidence based health policy, better insights in planning the best solutions, and generate ideas for further research.

This study has limitations as respondents might not give their exact observable fact towards some given questions, which leads to social desirability biases. This could be minimized by providing training to data collectors and conducted pre-test before actual data collection launched. A very shortage of previous similar studies was made comparison difficult.

\section{Conclusion}

In conclusion, this study finding pointed out the risk factors that were statistically significant associated with less likely to occurred diarrhea-related infant death includes; age of mother with <20 years old, unsafe drinking water storage, infants in households without point-of-use water treatment practices, households with unimproved sanitation status, unsafe disposing of child feaces and improper management of solid waste. On the other hand, households with improper management of liquid waste and household's practiced handwashing in fewer occasions (One to two critical times') were significantly associated with more likely to contribute lost of infant life due to diarrhea. The significant link of such risk factors could be one of the reasons for the contribution of uppermost death level of infants as the result of diarrhea. Therefore, efforts should be made to ensure intervention taking such risk factors into consideration which eventually can turn-down the consequence of the highest reported number of diarrhea-related infant death.

\section{Abbreviations}

AOR Adjusted Odds Ratio 
Cl Confidence Interval

COR Crude Odds Ratio

CSPro Census Statistics Program

EIWR Ethiopian Institute of Water Resources

ETB Ethiopian Birr

L/c/d Liters per capital per day

SD Standard Deviation

SPSS Statistical package for Social Sciences

WHO World Health Organization

\section{Declarations}

\section{Ethical approval and consent to participate}

Ethical approval to conduct the study was received from Ethics Review Board of Addis Ababa University Ethiopian Water Resource Institute and also ethical clearance was provided by the research ethics committee of Oromia Regional Health Bureau. Before the study begins, official permission was secured from each study district administrative as well as health offices. Informed consent from each study subjects were obtained after clear and adequate explanation of the objectives and purpose of the study were provided using the participant's information sheet. Personal data, in particular name, geographical and contact information about the respondent is kept and be encrypted to protect privacy and ensure confidentiality.

\section{Consent for publication}

Not applicable

\section{Availability of data and materials}

We confirm that all the relevant data are fully available. The dataset are accessible by contacting the corresponding author and provided upon a reasonable request.

\section{Competing interests}




\section{Funding Statement}

We have no received specific funding for this particular work

\section{Author Contributions}

S.M, A.W, D.G involved in conceptualization, data curation, format analysis, investigation, methodology, supervision, validation, visualization and editing. S.M contributed in project administration, resource, software and writing-original draft. All authors reviewed the manuscript.

\section{Authors reporting experiments on human data}

We confirm that all methods were carried out in accordance with relevant guidelines and regulations along with the approval.

\section{Acknowledgments}

We would like to special thank the West Harargehe zonal health department and the overall districts health offices (Chiro, Mieso, Gemechis, Tullo, Amibara and Awash Fentale) for their dedication and commitment in providing information and facilitate the study. We also extend our sincere thank for the study participants such as data collectors, supervisors and the respondents. Finally, our deepest gratitude and acknowledge goes to Addis Ababa University, EIWR and Care Ethiopia- West Hararghe Field Office for their technical and resources assistant.

\section{References}

1. Eliza H Humphreys et al. Prevention of diarrhoea in children with HIV infection or exposure to maternal HIV infection. Cochrane Library.htm. PubMed. 2010; DOI: 10.1002/14651858. CD008563.

2. Nelson R. Diarrhea Remains Leading Cause of Global Mortality and Morbidity. Infectious Disease Advisor, 2018. Available from: https://www.infectiousdiseaseadvisor.com

3. Troeger C, Colombara DV, Rao PC, et al. Global disability-adjusted life-year estimates of long-term health burden and undernutrition attributable to diarrhoeal diseases in children younger than 5 years. Lancet Glob Health. 2018;6(3):e255-e269. doi:10.1016/S2214-109X(18)30045-7.

4. Oria R., Pinkerton R., Lima A.A.M., Guerrant R.L. (2010) DALYs and Diarrhea. In: Preedy V.R., Watson R.R. (eds) Handbook of Disease Burdens and Quality of Life Measures. Springer, New York, NY. https://doi.org/10.1007/978-0-387-78665-0_69. 
5. Drroopesh. WHO updates fact sheet on Diarrhoeal diseases. communitymedicine4asses, 2017. Available from: https://communitymedicine4asses.com

6. Dadonaite B. More than half a million children die from diarrhea each year. How do we prevent this? Our World in Data. 2019. Available from: https://ourworldindata.org/childhood-diarrheal-diseases.

7. Colin Mathers. New estimates of the causes of child death under age 5. Colin Mathers. 2018. Available from: https://colinmathers.com/2018/12/09/new-estimates-of-the-causes-of-child-deathunder-age-5/.

8. Karambu S, Matiru V, Kiptoo M, Oundo J. Characterization and factors associated with diarrhoeal diseases caused by enteric bacterial pathogens among children aged five years and below attending Igembe District Hospital, Kenya. Pan Afr Med J. 2013. Available from:

https://www.ncbi.nlm.nih.gov/pmc/articles/PMC3932116/.

9. WHO. The world health report. 2002 |Available from: https://www.who.int/whr/2002/ chapter4/en/index7.html

10. Roth GA, Abate D, Abate KH, Abay SM, Abbafati C, Abbasi N, et al. Global, regional, and national agesex-specific mortality for 282 causes of death in 195 countries and territories, 1980-2017: a systematic analysis for the Global Burden of Disease Study 2017. The Lancet. $2018 \mathrm{Nov}$ 10;392(10159):1736-88.

11. Troeger C, Blacker BF, Khalil IA, Rao PC, Cao S, Zimsen SR, et al. Estimates of the global, regional, and national morbidity, mortality, and aetiologies of diarrhoea in 195 countries: a systematic analysis for the Global Burden of Disease Study 2016. Lancet Infect Dis. 2018 Nov 1;18 (11):1211-28.

12. Troeger C, Forouzanfar M, Rao PC, Khalil I, Brown A, Reiner RC, et al. Estimates of global, regional, and national morbidity, mortality, and aetiologies of diarrhoeal diseases: a systematic analysis for the Global Burden of Disease Study 2015. Lancet Infect Dis. 2017 Sep 1;17(9):909-48.

13. Parashar UD, Kilgore PE, Holman RC, Clarke MJ, Bresee JS, Glass RI. Diarrheal Mortality in US Infants: Influence of Birth Weight on Risk Factors for Death. Arch Pediatr Adolesc Med. 1998;152(1):47-51. doi:10.1001/archpedi.152.1.47.

14. CDC. The Management of Acute Diarrhea in Children: Oral Rehydration, Maintenance, and Nutritional Therapy. MMWR 1992;41(No.RR-16). Available from: https://www.cdc.gov/ mmwr/preview/mmwrhtml/00018677.htm

15. Bowen A, Agboatwalla M, Luby S, Tobery T, Ayers T, Hoekstra RM. Association between intensive handwashing promotion and child development in Karachi, Pakistan: a cluster randomized controlled trial. Arch Pediatr Adolesc Med. 2012 Nov;166(11):1037-44.

16. UNICEF: Diarrhoeal disease. UNICEF DATA. 2018. Available from: https://data.unicef.org /topic/childhealth/diarrhoeal-disease/.

17. WHO/UNICEF. Diarrhoeal diseases: The basics - Diarrhoea: Why children are still dying and what can be done - prevention and treatment measures. 2009. Available from: http://7pointplan.org/diarrhoealdiseases.html 
18. CDC. Global Diarrhea Burden: Global Water, Sanitation and Hygiene | Healthy Water. 2018. Available from: https://www.cdc.gov/healthywater/global/diarrhea-burden.html

19. Robert E Black et al. Where and why are 10 million children dying every year? PubMed. 2003. Available from: https://pubmed.ncbi.nlm.nih.gov/12842379/

20. UNICEF/WHO. Diarrhoea: why children are still dying and what can be done. 2009. Available from: https://www.who.int/maternal_child_adolescent/documents/9789241598415/en/

21. Victora C G et al. Water Supply, Sanitation and Housing in Relation to the Risk of Infant Mortality from Diarrhoea. International Journal of Epidemiology. 1988, 17:651-654

22. Gashaw $D$ et al. What factors aggravate prevalence of diarrhea among infants of 7-12 months in southern Ethiopia? Insight Medical Publishing Group.2017; Quality in Primary Care (2017) 25 (5): 321-325

23. FDRE Population Census Commission. Summary and Statistical Report of the 2007 population and Housing Census, 2008.

24. WHO, UNICEF. Core questions on drinking-water and sanitation for household surveys. JMP; 2006. Available from: http://awareness.who.int/water_sanitation_health/publications/ core_questions/en/

25. EDRE-Ministry of Water, Irrigation and Electric. Second Growth and Transformation National Plan for the Water Supply and Sanitation Sub-sector (2015/16 - 2019/20), 2015.

26. CDC. The safe water system: Safe storage of drinking water. National center for emerging and zoonotic infectious diseases, 2011. Available from http://www.cdc.gov/safewater

27. Lozano R, Naghavi M, Foreman K, Lim S, Shibuya K, Aboyans V, et al. Global and regional mortality from 235 causes of death for 20 age groups in 1990 and 2010: A systematic analysis for the Global Burden of Disease Study 2010. Lancet. 2012 Dec;380(9859):2095-128.

28. Peter H.Gleick. Dirty Water: Estimated Deaths from Water-Related Diseases 2000-2020. Pacific Institute for studies in development, Environment, and security.2002.

29. Levine MM, Nasrin D, Acacio S, et al. Diarrhoeal disease and subsequent risk of death in infants and children residing in low-income and middle-income countries: analysis of the GEMS case-control study and 12-month GEMS-1A follow-on study. The Lancet Global Health. 2019. DOl; https://doi.org/10.1016/S2214-109X(19)30541-8.

30. The Mother and Child Health and Education Trust. Diarrhoea, Diarrhea, Diarrea - What Is Diarrhoea and How to Prevent It - Rehydration Project. 2016.

31. Jm M, Dh E, Rc H, Je T, Ls C, Ud P. Risk factors for diarrhea-associated infant mortality in the United States, 2005-2007. Vol. 31, The Pediatric infectious disease journal. Pediatr Infect Dis J; 2012. Available from: https://pubmed.ncbi.nlm.nih.gov/22411052/.

32. Usman, Muhammed A.; Gerber, Nikolaus; von Braun, Joachim. The impact of drinking water quality and sanitation on child health: Evidence from rural Ethiopia, ZEF Discussion Papers on Development Policy, No. 221, University of Bonn, Center for Development Research (ZEF), Bonn. 2016. 
33. Sherman R. Johannesburg 2002 - World Submit on Sustainable Development Info. News. International Institute for sustainable Development. 2002 Available from: https://enb.iisd.org/wssd/infonews10(A).html

34. WaterDome 2002. Johannesburg Summit. Available from: http://www.waterdome.net/

35. Central Statistical Agency (CSA) [Ethiopia] and ICF. 2016. Ethiopia Demographic and Health Survey 2016. Addis Ababa, Ethiopia, and Rockville, Maryland, USA: CSA and ICF.

36. WHO. Household water treatment and safe storage. Available from: http://www.who.int/ water_sanitation_health/water-quality/household/en/.

37. Robert E Quick et al. Diarrhea prevention through household-level water disinfection and safe storage in Zambia. Am J Trop Med Hyg; 2002. DOI: 10.4269/ajtmh.2002.66.584 . Available from: https://pubmed.ncbi.nlm.nih.gov/12201595/.

38. Günther Fink, Isabel Günther, Kenneth Hill, The effect of water and sanitation on child health: evidence from the demographic and health surveys 1986-2007. International Journal of Epidemiology, Volume 40, Issue 5, October 2011, Pages 1196-1204, Available from: https://doi.org/10.1093/ije/dyr102

39. Cheng et al.: An ecological quantification of the relationships between water, sanitation and infant, child, and maternal mortality. Environmental Health. 2012; 11:4.

40. Troeger CE, Khalil IA, Blacker BF, Biehl MH, Albertson SB, Zimsen SRM, et al. Quantifying risks and interventions that have affected the burden of diarrhoea among children younger than 5 years: An analysis of the Global Burden of Disease Study 2017. Lancet Infect Dis. 2020; Jan 1;20(1):37-59.

41. Joe Brown, Sandy Cairncross, Jeroen H J Ensink.Water, sanitation, hygiene and enteric infections in children. BMJ Journal.2011; DOI http://dx.doi.org/10.1136/archdischild-2011-301528

42. Ezzati $M$ et al. Selected major risk factors and global and regional burden of disease. The Lancet. 2002; DOl:https://doi.org/10.1016/S0140-6736(02)11403-6

43. Val Curtis, Sandy Cairncross. Effect of washing hands with soap on diarrhoea risk in the community: A systematic review. PubMed.2003; The Lancet Infectious Diseases 3(5):275-81 DOI: 10.1016/S1473-3099(03)00606-6

44. Sandy Cairncross, Caroline Hunt, Sophie Boisson, Kristof Bostoen, Val Curtis, Isaac CH Fung, WolfPeter Schmidt, Water, sanitation and hygiene for the prevention of diarrhoea, International Journal of Epidemiology, Volume 39, Issue suppl_1, April 2010, Pages i193-i205, https://doi.org/10.1093/ije/dyq035

45. Oloruntoba E.O et al. Hygiene and Sanitation risk factors of diarrhoeal disease among under-five children in Ibadan, Nigeria. African Health Sciences Vol 14 Issue 4. 2014; DOI:http://dx.doi.org/ 10.4314/ahs.v14i4.32

46. Dagne $\mathrm{H}$ et al. Hand washing practice at critical times and its associated factors among mothers of under five children in Debark town, northwest Ethiopia. Italian Journal of Pediatrics. 2018; Available from: https://ijponline.biomedcentral.com/articles/10.1186/s13052-019-0713-z 
47. Hugh Waddington, Birte Snilstveit, Howard White, Lorna Fewtrell. Water, Sanitation and Hygiene intervention to combat childhood diarrhea in developing countries. International Initiative for Impact Evaluation. 2009.

\section{Tables}

Table 1: Frequency Distribution and Bivariate Analysis of Socio-demographic characteristics with Diarrhea cases and controls in Eastern Ethiopia, 2016-18

\begin{tabular}{|c|c|c|c|c|c|c|}
\hline \multirow[b]{2}{*}{ Socio-demographic Characteristics } & \multicolumn{2}{|c|}{ Case } & \multicolumn{2}{|c|}{ Control } & \multirow{2}{*}{$\begin{array}{c}\text { Crude Odds Ratio } \\
(95 \% \mathrm{CI})\end{array}$} & \multirow[t]{2}{*}{ P-value } \\
\hline & $\mathrm{n}$ & $\%$ & $\mathrm{n}$ & $\%$ & & \\
\hline \multicolumn{7}{|l|}{ Age of the mother } \\
\hline$<20$ Years old & 5 & 8.2 & 18 & 7.3 & $0.14(0.02,1.05)$ & 0.056 \\
\hline 20-34 Years old & 55 & 90.2 & 200 & 82.0 & $1.01(0.36,2.84)$ & 0.985 \\
\hline$\geq 35 y e a r s$ old & 1 & 1.6 & 26 & 10.7 & 1 & - \\
\hline \multicolumn{7}{|l|}{ Parity } \\
\hline $1^{\text {st }}$ & 22 & 36.0 & 72 & 29.5 & $0.97(0.46,2.06)$ & 0.939 \\
\hline $2^{\text {nd }}-4^{\text {th }}$ & 27 & 44.3 & 118 & 48.4 & $1.34(0.71,2.52)$ & 0.372 \\
\hline$\geq 5$ & 12 & 19.7 & 54 & 22.1 & 1 & - \\
\hline \multicolumn{7}{|l|}{ Household Family Size } \\
\hline$\geq 5$ & 18 & 29.5 & 91 & 37.3 & $1.42(0.77,2.61)$ & 0.258 \\
\hline$<5$ & 43 & 70.5 & 153 & 62.7 & 1 & - \\
\hline \multicolumn{7}{|l|}{ Maternal Marital Status } \\
\hline Married & 59 & 96.7 & 239 & 98.0 & $1.62(0.31,8.56)$ & 0.570 \\
\hline Unmarried & 2 & 3.3 & 5 & 2.0 & 1 & - \\
\hline \multicolumn{7}{|l|}{ Ethnicity } \\
\hline Oromo & 55 & 90.2 & 213 & 87.3 & $0.75(0.29,1.89)$ & 0.540 \\
\hline Others & 6 & 9.8 & 31 & 12.7 & 1 & - \\
\hline \multicolumn{7}{|l|}{ Religion } \\
\hline Muslim & 60 & 98.4 & 216 & 88.5 & $5.65(0.75,42.9)$ & 0.094 \\
\hline Christian & 1 & 1.6 & 28 & 11.5 & 1 & - \\
\hline \multicolumn{7}{|l|}{ Mother's level of education } \\
\hline No education & 54 & 88.5 & 181 & 74.2 & $0.37(0.16,0.86)^{*}$ & 0.021 \\
\hline Educated & 7 & 11.5 & 63 & 25.8 & 1 & - \\
\hline \multicolumn{7}{|l|}{ Spouse's level of education } \\
\hline No education & 48 & 78.7 & 159 & 65.2 & $0.51(0.26,0.98)^{*}$ & 0.046 \\
\hline Educated & 13 & 21.3 & 85 & 34.8 & 1 & - \\
\hline \multicolumn{7}{|l|}{ Mother's Occupation } \\
\hline Housewife & 55 & 90.2 & 221 & 90.6 & $1.05(0.41,2.69)$ & 0.922 \\
\hline Others & 6 & 9.8 & 23 & 9.4 & 1 & - \\
\hline \multicolumn{7}{|l|}{ Spouse's Occupation } \\
\hline Farmer/own farm labor & 55 & 90.2 & 209 & 85.7 & $0.65(0.26,1.63)$ & 0.359 \\
\hline Others & 6 & 9.8 & 35 & 14.3 & 1 & - \\
\hline \multicolumn{7}{|l|}{ Households Average Monthly Income (ETB) } \\
\hline$<570 \mathrm{ETB}$ & 33 & 54.1 & 120 & 49.2 & $0.82(0.47,1.44)$ & 0.492 \\
\hline$\geq 570 \mathrm{ETB}$ & 28 & 45.9 & 124 & 50.8 & 1 & - \\
\hline
\end{tabular}

* Risk factors significantly associated at $p$-value $<0.05$ 
Table 2: Frequency Distribution and Bivariate Analysis of Drinking Water Access and Use with Diarrhea cases and controls in Eastern Ethiopia, 2016-18

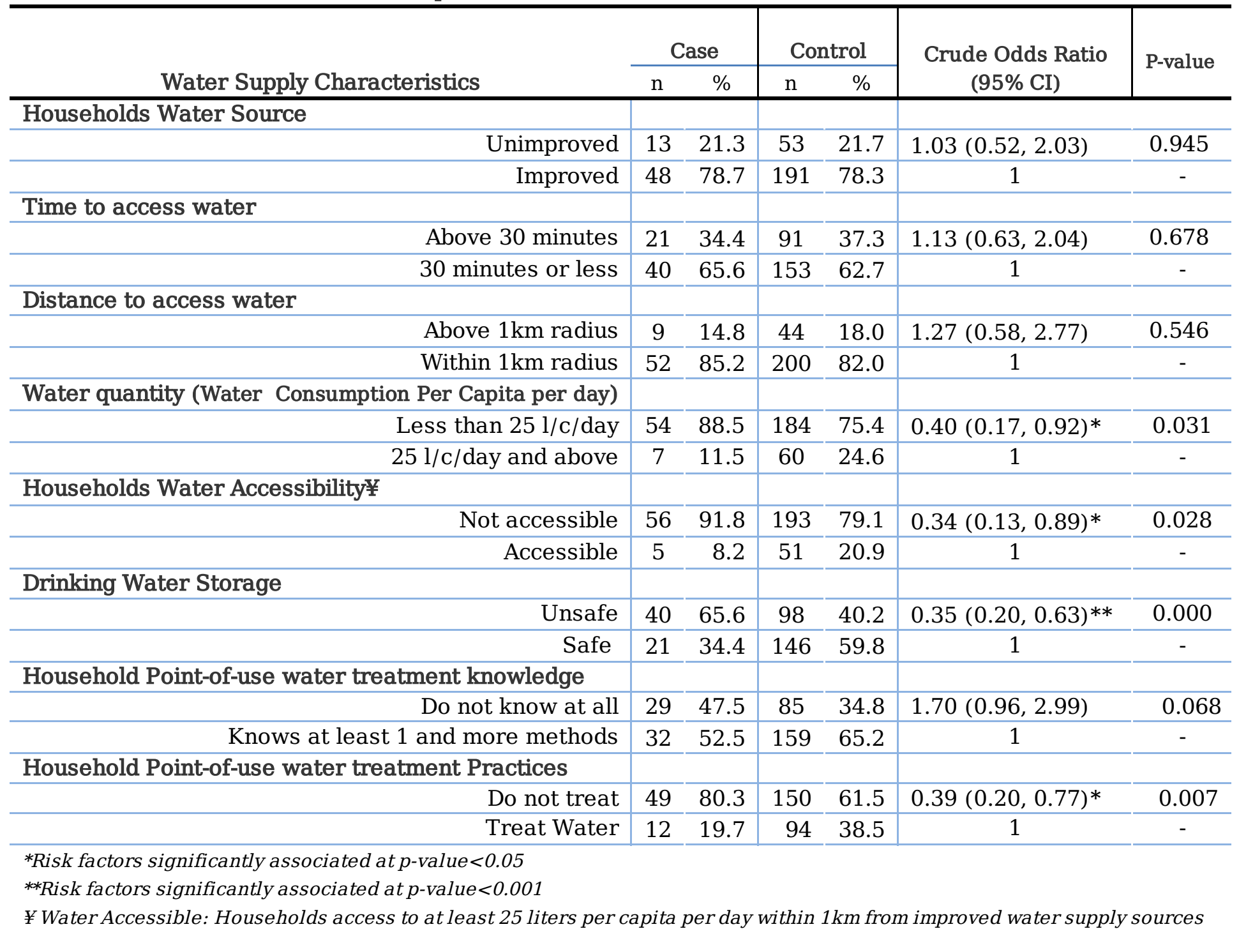

Table 3: Frequency Distribution and Bivariate Analysis of Sanitation with Diarrhea cases and controls in Eastern Ethiopia, 2016-18 


\begin{tabular}{|c|c|c|c|c|c|c|}
\hline \multirow{2}{*}{$\begin{array}{l}\text { Sanitation } \\
\text { Characteristics }\end{array}$} & \multicolumn{2}{|c|}{ Case } & \multicolumn{2}{|c|}{ Control } & \multirow{2}{*}{$\begin{array}{c}\text { Crude Odds Ratio } \\
(95 \% \mathrm{CI})\end{array}$} & \multirow{2}{*}{ P-value } \\
\hline & $\mathrm{n}$ & $\%$ & $\mathrm{n}$ & $\%$ & & \\
\hline \multicolumn{7}{|l|}{ Latrine Ownership } \\
\hline No latrine & 21 & 34.4 & 58 & 23.8 & $0.67(0.37,1.22)$ & 0.188 \\
\hline Have Latrine & 40 & 65.6 & 186 & 76.2 & 1 & - \\
\hline \multicolumn{7}{|l|}{ Open Defecation Practices } \\
\hline Yes & 13 & 21.3 & 49 & 20.1 & $0.93(0.47,1.85)$ & 0.831 \\
\hline No & 48 & 78.7 & 195 & 79.9 & 1 & - \\
\hline \multicolumn{7}{|l|}{ Household Latrine Utilization } \\
\hline No & 24 & 39.3 & 70 & 28.7 & $0.62(0.35,1.11)$ & 0.109 \\
\hline Yes & 37 & 60.7 & 174 & 71.3 & 1 & - \\
\hline \multicolumn{7}{|l|}{ Household Latrine Cleanness } \\
\hline No & 18 & 29.5 & 64 & 26.2 & $1.15(0.55,2.39)$ & 0.718 \\
\hline Yes & 24 & 39.3 & 121 & 49.6 & 1 & - \\
\hline Not applicable & 19 & 31.2 & 59 & 24.2 & & \\
\hline \multicolumn{7}{|l|}{ Hand washing Facility near to latrine } \\
\hline No & 31 & 50.8 & 63 & 25.8 & $0.65(0.33,1.28)$ & 0.217 \\
\hline Yes & 11 & 18.0 & 122 & 50.0 & 1 & - \\
\hline Not applicable & 19 & 31.2 & 59 & 24.2 & & \\
\hline \multicolumn{7}{|l|}{ Sanitation Status } \\
\hline Unimproved sanitation & 51 & 83.6 & 162 & 66.4 & $0.39(0.19,0.80)^{*}$ & 0.011 \\
\hline Improved sanitation & 10 & 16.4 & 82 & 33.6 & 1 & - \\
\hline \multicolumn{7}{|l|}{ Households Disposing of Child feaces } \\
\hline Unsafe & 43 & 70.5 & 97 & 39.8 & $0.28(0.15,0.51)^{* *}$ & 0.000 \\
\hline Safe & 18 & 29.5 & 147 & 60.2 & 1 & - \\
\hline \multicolumn{7}{|l|}{ Solid waste Management } \\
\hline Improper management & 33 & 54.1 & 195 & 79.9 & $0.21(0.12,0.39)^{*}$ & 0.000 \\
\hline Proper management & 28 & 45.9 & 49 & 20.1 & 1 & - \\
\hline \multicolumn{7}{|l|}{ Liquid waste Management } \\
\hline Improper management & 50 & 82.0 & 140 & 57.4 & $3.38(1.68,6.80)^{*}$ & 0.001 \\
\hline Proper management & 11 & 18.0 & 104 & 42.6 & 1 & - \\
\hline
\end{tabular}

Table 4: Frequency Distribution and Bivariate Analysis of Hygiene Characteristics with Diarrhea cases and controls in Eastern Ethiopia, 2016-18 


\begin{tabular}{|c|c|c|c|c|c|c|}
\hline \multirow{2}{*}{$\begin{array}{l}\text { Hygiene } \\
\text { Characteristics }\end{array}$} & \multicolumn{2}{|c|}{ Case } & \multicolumn{2}{|c|}{ Control } & \multirow{2}{*}{$\begin{array}{l}\text { Crude Odds Ratio } \\
(95 \% \mathrm{CI})\end{array}$} & \multirow{2}{*}{$\begin{array}{c}\text { P- } \\
\text { value }\end{array}$} \\
\hline & $\mathrm{n}$ & $\%$ & $\mathrm{n}$ & $\%$ & & \\
\hline \multicolumn{7}{|l|}{ Critical Time of Hand washing Practices } \\
\hline Do not practiced hand washing in any critical time & 18 & 29.5 & 24 & 9.8 & $\begin{array}{l}0.38 \quad(0.16, \\
0.89) * \quad \quad\end{array}$ & 0.025 \\
\hline $\begin{array}{r}\text { Practiced less than three critical time of Hand } \\
\text { washing }\end{array}$ & 36 & 59.0 & 145 & 59.5 & $\begin{array}{l}3.02 \quad(1.48, \\
6.16) * \quad\end{array}$ & 0.002 \\
\hline Practiced 3 and more critical time of Hand Washing & 7 & 11.5 & 75 & 30.7 & 1 & - \\
\hline \multicolumn{7}{|l|}{ Agents used during Hand washing } \\
\hline Not used any agents & 51 & 83.6 & 78 & 32.0 & $\begin{array}{l}1.91 \\
3.43)^{*}\end{array}$ & 0.030 \\
\hline Used (water + soap or ash/abrasives) & 10 & 16.4 & 166 & 68.0 & 1 & - \\
\hline
\end{tabular}

Table 5: Bivariate and Multivariable Conditional Logistic Regression for the risk factors associated with diarrhea-related Cases and Controls in Eastern Ethiopia, 2016-18 


\begin{tabular}{|c|c|c|c|c|c|c|}
\hline \multirow{2}{*}{ Variables } & \multicolumn{2}{|c|}{ Case } & \multicolumn{2}{|c|}{ Control } & \multicolumn{2}{|c|}{ Odds Ratio (95\% CI) } \\
\hline & $\mathrm{n}$ & $\%$ & $\mathrm{n}$ & $\%$ & Crude & Adjusted \\
\hline \multicolumn{7}{|l|}{ Age of the mother } \\
\hline$<20$ Years old & 5 & 8.2 & 18 & 7.3 & $\begin{array}{l}0.14(0.02 \\
1.05)\end{array}$ & $\begin{array}{l}0.05(0.01 \\
0.47) *\end{array}$ \\
\hline 20-34 Years old & 55 & 90.2 & 200 & 82.0 & $\begin{array}{l}1.01(0.36 \\
2.84)\end{array}$ & $\begin{array}{l}1.59(0.37 \\
6.75)\end{array}$ \\
\hline$\geq 35$ years old & 1 & 1.6 & 26 & 10.7 & 1 & 1 \\
\hline \multicolumn{7}{|l|}{ Religion } \\
\hline Muslim & 60 & 98.4 & 216 & 88.5 & $\begin{array}{l}5.65(0.75 \\
42.9)\end{array}$ & $\begin{array}{l}1.00(0.11 \\
9.47)\end{array}$ \\
\hline Christian & 1 & 1.6 & 28 & 11.5 & 1 & 1 \\
\hline \multicolumn{7}{|l|}{ Mother's level of education } \\
\hline No education & 54 & 88.5 & 181 & 74.2 & $\begin{array}{l}0.37(0.16 \\
0.86)^{*}\end{array}$ & $\begin{array}{l}0.50(0.12 \\
2.15)\end{array}$ \\
\hline Educated at some level & 7 & 11.5 & 63 & 25.8 & 1 & 1 \\
\hline \multicolumn{7}{|l|}{ Spouse's level of education } \\
\hline No education & 48 & 78.7 & 159 & 65.2 & $\begin{array}{l}0.51(0.26 \\
0.98) *\end{array}$ & $\begin{array}{l}0.72(0.21 \\
2.44)\end{array}$ \\
\hline Educated at Some level of schooling & 13 & 21.3 & 85 & 34.8 & 1 & 1 \\
\hline \multicolumn{7}{|l|}{$\begin{array}{l}\text { Water quantity (Water Consumption Per Capita } \\
\text { per day) }\end{array}$} \\
\hline Less than 25 l/c/day & 54 & 88.5 & 184 & 75.4 & $\begin{array}{c}0.40(0.17 \\
0.92)^{*}\end{array}$ & $\begin{array}{l}0.21(0.03 \\
1.69)\end{array}$ \\
\hline 25 l/c/day and above & 7 & 11.5 & 60 & 24.6 & 1 & 1 \\
\hline \multicolumn{7}{|l|}{ Households Water Accessibility $¥$} \\
\hline Not accessible & 56 & 91.8 & 193 & 79.1 & $\begin{array}{l}0.34(0.13 \\
0.89) *\end{array}$ & $\begin{array}{c}1.04(0.10 \\
10.6)\end{array}$ \\
\hline Accessible & 5 & 8.2 & 51 & 20.9 & 1 & 1 \\
\hline \multicolumn{7}{|l|}{ Drinking Water Storage } \\
\hline Unsafe & 40 & 65.6 & 98 & 40.2 & $\begin{array}{c}0.35(0.20 \\
0.63) * *\end{array}$ & $\begin{array}{l}0.38(0.18 \\
0.81)^{*}\end{array}$ \\
\hline Safe & 21 & 34.4 & 146 & 59.8 & 1 & 1 \\
\hline \multicolumn{7}{|l|}{$\begin{array}{l}\text { Household Point-of-use water treatment } \\
\text { knowledge }\end{array}$} \\
\hline Do not know at all & 29 & 47.5 & 85 & 34.8 & $\begin{array}{l}1.70(0.96 \\
2.99)\end{array}$ & $\begin{array}{l}1.16(0.45 \\
2.97)\end{array}$ \\
\hline Knows at least 1 and more methods & 32 & 52.5 & 159 & 65.2 & 1 & 1 \\
\hline \multicolumn{7}{|l|}{$\begin{array}{l}\text { Household Point-of-use water treatment } \\
\text { Practices }\end{array}$} \\
\hline Do not treat & 49 & 80.3 & 150 & 61.5 & $\begin{array}{l}0.39(0.20 \\
0.77)^{*}\end{array}$ & $\begin{array}{l}0.21(0.08 \\
0.61)^{*}\end{array}$ \\
\hline Treat Water & 12 & 19.7 & 94 & 38.5 & 1 & 1 \\
\hline
\end{tabular}

Table 5 (Continued) 


\begin{tabular}{|c|c|c|c|c|c|c|}
\hline \multirow[b]{2}{*}{ Variables } & \multicolumn{2}{|c|}{ Case } & \multicolumn{2}{|c|}{ Control } & \multicolumn{2}{|c|}{ Odds Ratio (95\% CI) } \\
\hline & $\mathrm{n}$ & $\%$ & $\mathrm{n}$ & $\%$ & Crude & Adjusted \\
\hline \multicolumn{7}{|l|}{ Latrine Ownership } \\
\hline No latrine & 21 & 34.4 & 58 & 23.8 & $0.67(0.37,1.22)$ & $1.47(0.18,11.8)$ \\
\hline Have Latrine & 40 & 65.6 & 186 & 76.2 & 1 & 1 \\
\hline \multicolumn{7}{|l|}{ Household Latrine Utilization } \\
\hline \multicolumn{7}{|l|}{ No } \\
\hline & 24 & 39.3 & 70 & 28.7 & $0.62(0.35,1.11)$ & $0.26(0.04,1.69)$ \\
\hline Yes & 37 & 60.7 & 174 & 71.3 & 1 & 1 \\
\hline \multicolumn{7}{|l|}{ Hand washing Facility near to latrine } \\
\hline No & 31 & 50.8 & 63 & 25.8 & $0.65(0.33,1.28)$ & $0.15(0.01,2.36)$ \\
\hline Yes & 11 & 18.0 & 122 & 50.0 & 1 & 1 \\
\hline \multicolumn{7}{|l|}{ Sanitation Status } \\
\hline Unimproved sanitation & 51 & 83.6 & 162 & 66.4 & $0.39(0.19,0.80)^{*}$ & $\begin{array}{c}0.36(0.13 \\
1.00)^{*}\end{array}$ \\
\hline Improved sanitation & 10 & 16.4 & 82 & 33.6 & 1 & 1 \\
\hline \multicolumn{7}{|l|}{ Households Disposing of Child feaces } \\
\hline Unsafe & 43 & 70.5 & 97 & 39.8 & $\begin{array}{l}0.28(0.15 \\
0.51)^{* *}\end{array}$ & $\begin{array}{l}0.34(0.15 \\
0.81)^{*}\end{array}$ \\
\hline Safe & 18 & 29.5 & 147 & 60.2 & 1 & 1 \\
\hline \multicolumn{7}{|l|}{ Solid Waste Management } \\
\hline Improper management & 33 & 54.1 & 195 & 79.9 & $0.21(0.12,0.39) *$ & $\begin{array}{l}0.29(0.13 \\
0.66)^{*}\end{array}$ \\
\hline Proper management & 28 & 45.9 & 49 & 20.1 & 1 & 1 \\
\hline \multicolumn{7}{|l|}{ Liquid Waste Management } \\
\hline Improper management & 50 & 82.0 & 140 & 57.4 & $3.38(1.68,6.80) *$ & $\begin{array}{l}3.43(1.34 \\
8.76)^{*}\end{array}$ \\
\hline Proper management & 11 & 18.0 & 104 & 42.6 & 1 & 1 \\
\hline \multicolumn{7}{|l|}{ Critical Time of Hand washing Practices } \\
\hline Do not practiced in any critical time & 18 & 29.5 & 24 & 9.8 & $0.38(0.16,0.89) *$ & $0.64(0.22,1.87)$ \\
\hline $\begin{array}{r}\text { Practiced less than three critical } \\
\text { times }\end{array}$ & 36 & 59.0 & 145 & 59.5 & $3.02(1.48,6.16) *$ & $\begin{array}{l}3.04(1.13 \\
\quad 8.17)^{*}\end{array}$ \\
\hline Practiced in 3 and more critical time & 7 & 11.5 & 75 & 30.7 & 1 & 1 \\
\hline \multicolumn{7}{|l|}{ Agents used during Hand washing } \\
\hline Not used any agents & 51 & 83.6 & 78 & 32.0 & $1.91(1.07,3.43)^{*}$ & $1.92(0.86,4.29)$ \\
\hline Used (water + soap or ash/abrasives) & 10 & 16.4 & 166 & 68.0 & 1 & 1 \\
\hline
\end{tabular}

*Risk factors significantly associated at p-value $<0.05$

**Risk factors significantly associated at p-value $<0.001$ 


\section{Supplementary Files}

This is a list of supplementary files associated with this preprint. Click to download.

- RiskfactorDDrawdata.sav 